\title{
RELAÇÃO ENTRE COMPONENTES NATURAIS E URBANOS E CARACTERÍSTICAS DO CAMPO TÉRMICO PARA DEFINIÇÃO DE TOPOCLIMAS NO MUNICÍPIO DE JUIZ DE FORA-MG
}

\author{
ASSIS, Debora Couto de - cassis.debora@gmail.com \\ Universidade Federal de Minas Gerais / UFMG \\ JARDIM, Carlos Henrique - cjardim@yahoo.com \\ Universidade Federal de Minas Gerais / UFMG
}

\begin{abstract}
RESUMO: Pesquisas na área de climatologia em cidades médias, em processo de desenvolvimento, são importantes para que haja manutenção da qualidade ambiental de maneira preventiva. Nesse sentido, o objetivo deste artigo foi trazer dados e informações sobre a identificação e caracterização do campo térmico no município de Juiz de Fora, considerando as variações de temperatura do ar e relação com aspectos de uso do solo e morfologia do terreno, para elaboração do esboço de unidades climáticas. Os procedimentos metodológicos incluíram revisão teórica, análise das condições térmicas por sensores remotos, aquisição e tratamento de dados obtidos em campo, processamento de dados espaciais e síntese dos dados. Os resultados evidenciaram que a porção leste do município registrou menores valores de temperatura do ar, relacionada a presença de fragmentos de vegetação e cursos d'agua, e o ponto com menor temperatura média foi identificado na zona rural, em fragmento de mata ciliar. A temperatura máxima foi localizada no Distrito Industrial. As 34 classes topoclimáticas identificadas resultaram de combinações existentes entre temperatura, uso do solo e morfologia do terreno. A classe de uso do solo associada a áreas de pastagens possui grande relevância na constituição das zonas térmicas do município.
\end{abstract}

PALAVRAS-CHAVE: unidades climáticas; monitoramento de campo; campo térmico.

RELATIONSHIP BETWEEN NATURAL AND URBAN COMPONENTS AND CHARACTERISTICS OF THE THERMAL FIELD FOR DEFINITION OF TOPOCLIMES IN THE MUNICIPALITY OF JUIZ DE FORA-MG

\begin{abstract}
Climatology research in medium-sized cities is important to maintain environmental quality. In this sense, the objective of this article was to bring data and information about the identification and characterization of the thermal field in the city of Juiz de Fora (Minas Gerais - Brazil), considering the variations of air temperature and relationship with land use and land morphology aspects, for the elaboration of climate units sketch. Methodological procedures included theoretical review, analysis of remote sensor thermal conditions, acquisition and treatment of field data, spatial data processing and data synthesis. The results showed that the eastern portion of the municipality recorded the lowest values of air temperature, related to the presence of vegetation fragments and waterways, and the point with the lowest average temperature was identified in the rural area, in a riparian forest fragment. The maximum temperature was located in the Industrial District. The 34 topoclimatic classes identified resulted from existing combinations of temperature, land use and terrain morphology. The class of land use associated with pasture areas has great relevance in the constitution of the thermal zones of the municipality.
\end{abstract}

KEYWORDS: climatic units; field monitoring; thermal field. 
RELACIÓN ENTRE COMPONENTES Y CARACTERÍSTICAS NATURALES Y URBANAS DEL CAMPO TÉRMICO PARA LA DEFINICIÓN DE TOPOCLIMAS EN EL MUNICIPIO DE JUIZ DE FORA-MG

RESUMEN: La investigación de climatología en ciudades medianas es importante para mantener preventivamente la calidad ambiental. En este sentido, el objetivo de este artículo fue aportar datos e información sobre la identificación y caracterización del campo térmico en la ciudad de Juiz de Fora (Minas Gerais - Brasil), considerando las variaciones de temperatura del aire y la relación con el uso del suelo y los aspectos de la morfología del suelo, para la elaboración de bosquejo de unidades climáticas. Los procedimientos metodológicos incluyeron revisión teórica, análisis de condiciones térmicas por sensores remotos, adquisición y tratamiento de datos de campo, procesamiento de datos espaciales y síntesis de datos. Los resultados mostraron que la porción oriental del municipio registró los valores más bajos de temperatura del aire, relacionados con la presencia de fragmentos de vegetación y vías fluviales, y el punto con la temperatura promedio más baja se identificó en el área rural, en un fragmento de bosque ribereño. La temperatura máxima se ubicó en el Distrito Industrial. Las 34 clases topoclimáticas identificadas resultaron de combinaciones existentes de temperatura, uso del suelo y morfología del terreno. La clase de uso de la tierra asociada con las áreas de pasto tiene una gran relevancia en la constitución de las zonas termales del municipio.

PALABRAS CLAVE: unidades climáticas; monitoreo de campo; campo termal.

\section{INTRODUÇÃO E REVISÃO DE LITERATURA}

O crescimento das cidades está relacionado ao aumento do número de moradias associado a ocupação da terra, ordenada sob a lógica dos agentes de produção do espaço urbano, resultando na permuta de paisagens naturais por espaços cada vez mais artificializados dependentes de intervenção humana.

Para além das mudanças na esfera urbana, as atividades agropastoris tiveram papel relevante nas cidades mineiras, tanto na economia quanto na proliferação de áreas degradadas, uma vez que grandes fragmentos de mata Atlântica cederam lugar para lavoura, principalmente do café no caso do município de Juiz de Fora.

De acordo com o Anuário Estatístico de Juiz de Fora de 2005, a microrregião teve a maior parte de suas florestas nativas (Mata Atlântica) devastada pelas atividades de cafeicultura e criação de áreas de pastagens, resultando na fragmentação desse domínio. Parte desses fragmentos se encontram, nos dias de hoje, em regeneração no limite entre a malha urbana e áreas rurais, e a existência de Unidades de Conservação (UCs). A conservação desses espaços remanescentes estão aquém de constituir numa proteção efetiva da cobertura florestal, assim como promover condições necessárias para uma dinâmica ecológica que restabeleça as relações ecológicas outrora existentes nessa região.

Assim, revela-se que as atividades humanas geram disfunções de difícil gestão e correção, além de expor a condições de vulnerabilidade a população menos favorecida, pois essa parcela da sociedade geralmente é induzida a se estabelecer nos espaços mais degradados da cidade. Isto se justifica pelo processo de produção econômica, o qual conduz investimentos de infraestrutura para áreas de maior interesse econômico em detrimento daquelas menos valorizadas. E são justamente esses espaços que possuem maior demanda por esse tipo de investimento. 
Nesse sentindo faz-se necessário lançar mão de conceitos que auxiliem na compreensão das modificações introduzidas pela ação humana. Sendo assim, têm-se a paisagem como categoria elementar, entendida por Sauer como um "Organismo complexo, feito da associação específica de formas e apreendida pela análise morfológica" (SAUER,1925), que deve ser compreendida através de sua forma, posição, estrutura e funcionamento.

Como modelo explicativo da paisagem foi proposto o conceito de geossistema que, segundo Monteiro (1978), define-se como um sistema singular, complexo, onde interagem os componentes físicos, químicos, biológicos e socioeconômicos. Em termos hierárquicos, o geossistema situa-se entre as realidades locais e regionais, cuja dimensão por si só o coloca no patamar de unidade natural responsável pelo insumo energético de sistemas subjacentes e dependentes de menor dimensão, incluindo os sistemas socioeconômicos (cidades, áreas rurais, vias de acesso, sistemas de transmissão de energia, portos etc.).

Dessa forma, entendendo o clima como parte constituinte do sistema, Ribeiro (1993) afirma que o fenômeno climático é resultado da inter-relação de trocas energéticas recíprocas e interdependentes de fenômenos de natureza diversas. Essas trocas estão diretamente relacionadas à entrada de energia através da radiação solar e como as superfícies respondem a recepção dessa energia, na forma de ondas curtas, e a irradiação para atmosfera na forma de ondas longas.

Nesse processo pode-se destacar as propriedades físicas e dinâmicas dos componentes em superfície que, segundo abordagem de Ribeiro (1993), incluem-se os microclimas definidos "através da magnitude das trocas gasosas e energéticas entre as feições ou estruturas particularizadas (inclusive objetos, plantas e animais) dispostas na superfície da Terra e o ar que as envolve" e os topoclimas entendidos como "derivação do clima local devida à rugosidade do terreno, que tem como consequência a energização diferenciada do terreno, durante o período diurno, para as diversas faces de exposição à radiação solar".

Portanto, o clima, hierarquizado em microclimas e topoclimas, foco escalar da presente pesquisa, inclui-se no interior desse mosaico multifacetado dos geossistemas, constituído por formas, materiais, processos e funções diferenciadas, a partir do qual é possível a obtenção de indicadores que denunciem alterações introduzidas no meio, em adição ao substrato natural da paisagem, caracterizadas pelo acúmulo de modificações nos pontos onde o sistema é mais susceptível ao desencadeamento de impactos negativos.

Isso, evidentemente, não significa que as variações de temperatura encontradas no interior de áreas urbanas e/ou obtidas de forma simultânea em áreas urbanas, rurais e remanescentes de áreas florestais, se constituam nelas mesmas como o maior dos problemas em termos de impactos negativos. Muitas localidades no Brasil e no mundo experimentam habitualmente variações horário-diárias, com pouco ou nenhuma relação com alterações antrópicas, muito maiores do que aquelas detectadas numa centena de outras cidades pelo mundo afora. A problemática deve ser vista de forma integrada a outros tipos de impactos negativos, ou seja, não separando problemas relacionados a conforto térmico daqueles ligados a poluição do ar e resultantes de impactos pluviais. 
Nesse sentido, deve-se destacar a importância de estudos que diagnostiquem variações térmicas no interior de cidades médias, que se encontram em processo de desenvolvimento, para que haja manutenção da qualidade ambiental dessas cidades de maneira preventiva, como evidencia Amorim e Barbosa (2012). São nas cidades médias onde se encontram as melhores condições de intervenções de um planejamento ambiental urbano prévio, que considere a realidade climática das mesmas.

As condições climáticas do município de Juiz de Fora já foram estudadas em diferentes escalas, principalmente no que tange ao clima urbano, como Pimentel e Ferreira (2019) na elaboração de modelos geoespaciais na investigação do comportamento térmico de um recorte da cidade. Já no trabalho de Oliveira et.al (2014) são delimitadas as unidades climáticas da bacia do Rio Preto anteriormente denominada bacia do Rio Paraibuna, onde se encontra Juiz de Fora, caracterizando-se como pouco chuvosa e quente. Mesmo diante dos diversos projetos de pesquisa desenvolvidos no município, ainda se faz necessário trabalhos que investiguem a realidade climática do município como um todo, não apenas focando nas áreas urbanas, mas que contemplem áreas rurais e naturais, mais representativas espacialmente do que as áreas urbanas.

Diante desse contexto, o presente artigo tem como objetivo trazer dados e informações que permitam a identificação e caracterização do campo térmico no município de Juiz de Fora, considerando as variações de temperatura do ar obtidas em diferentes pontos amostrais entre os meses de julho e setembro de 2019, relacionando aspectos de uso e de cobertura do solo e morfologia do terreno, visando a elaboração de um esboço de unidades topoclimáticas.

\section{CARACTERIZAÇÃO DA ÁREA DE ESTUDO}

Juiz de Fora está localizada na zona da mata mineira inserida na bacia hidrográfica do Rio Paraíba do Sul (Figura 1). O município possui extensão territorial de $1435,7 \mathrm{~km}^{2}$, com total de 516 mil habitantes, sendo que $98 \%$ é considerada urbana (IBGE,2010). A cidade possui relevância regional devido a função de prestadora de serviços para os municípios das proximidades, além de sua localização estratégica no eixo entre as capitais Rio de Janeiro e Belo Horizonte.

O município se divide em quatro distritos, sendo estes: Juiz de Fora (sede), Torreões, Rosário de Minas e Sarandira, que compreendem extensão territorial de $725,975 \mathrm{~km}^{2}$. Juiz de Fora (Minas Gerais) se caracteriza por apresentar grandes variações de altitudes, formação de inúmeros anfiteatros e planícies intermontanas, com altitudes que chegam a $1100 \mathrm{~m}$ nos pontos mais elevados, 670 a $750 \mathrm{~m}$ no fundo do vale do rio Paraibuna e níveis médios em torno de $800 \mathrm{~m}$. O levantamento da etapa de diagnóstico do Plano Diretor Participativo da portaria 08615/13, realizou um mapeamento de uso e cobertura da Terra, no qual a pastagem apresenta-se em proeminência, somando 58,5\% da área total do município, seguida pela classe de uso de mata nativa correspondente a $27,5 \%$ da extensão absoluta. 


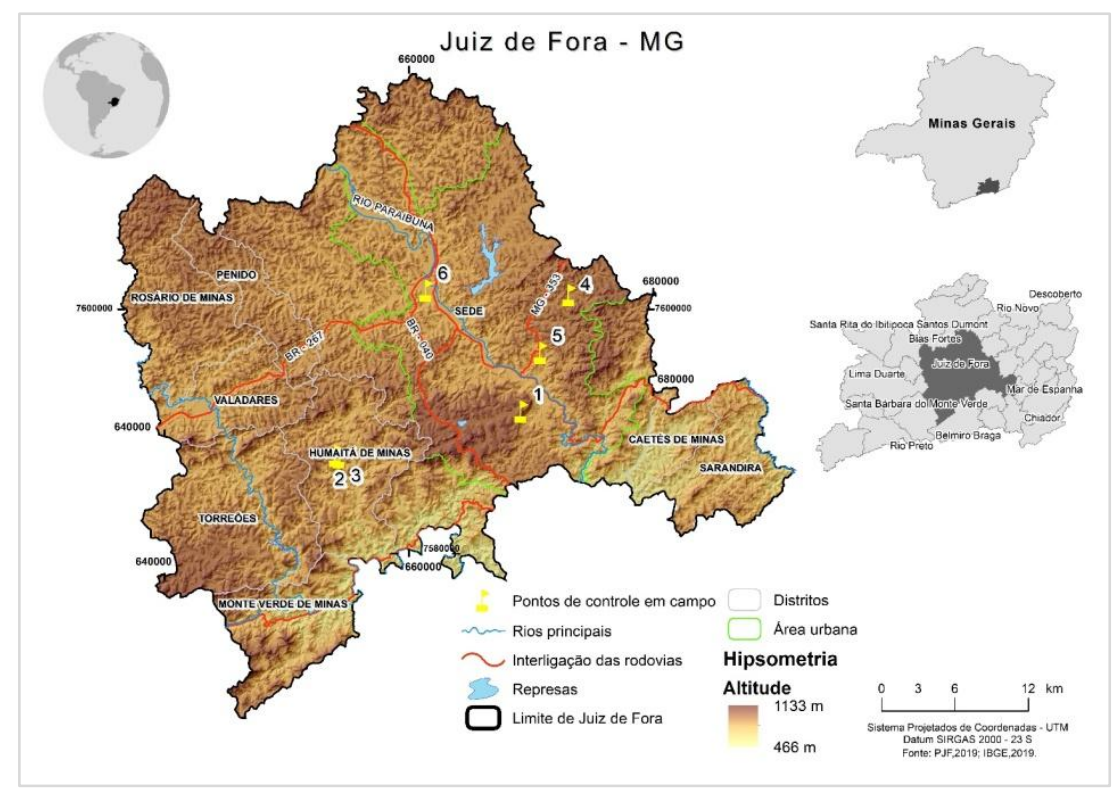

Figura 1 - Localização da área de estudo. Organizado pelos autores.

Deve-se destacar a área edificada que ocupa 8,5\% da área total, porém, esse percentual não se distribui de forma homogênea por todo município, sendo concentrado em porções de Juiz de Fora como é possível observar na figura 2. Com menores expressividades apresentam-se outros tipos de uso como: Silvicultura $(3,6 \%)$, Unidade de Conservação (0,6\%), Corpos d'água $(0,48 \%)$, Solo Exposto (0,48\%), Agricultura (0,15\%) e Extração Mineral (0,04\%).

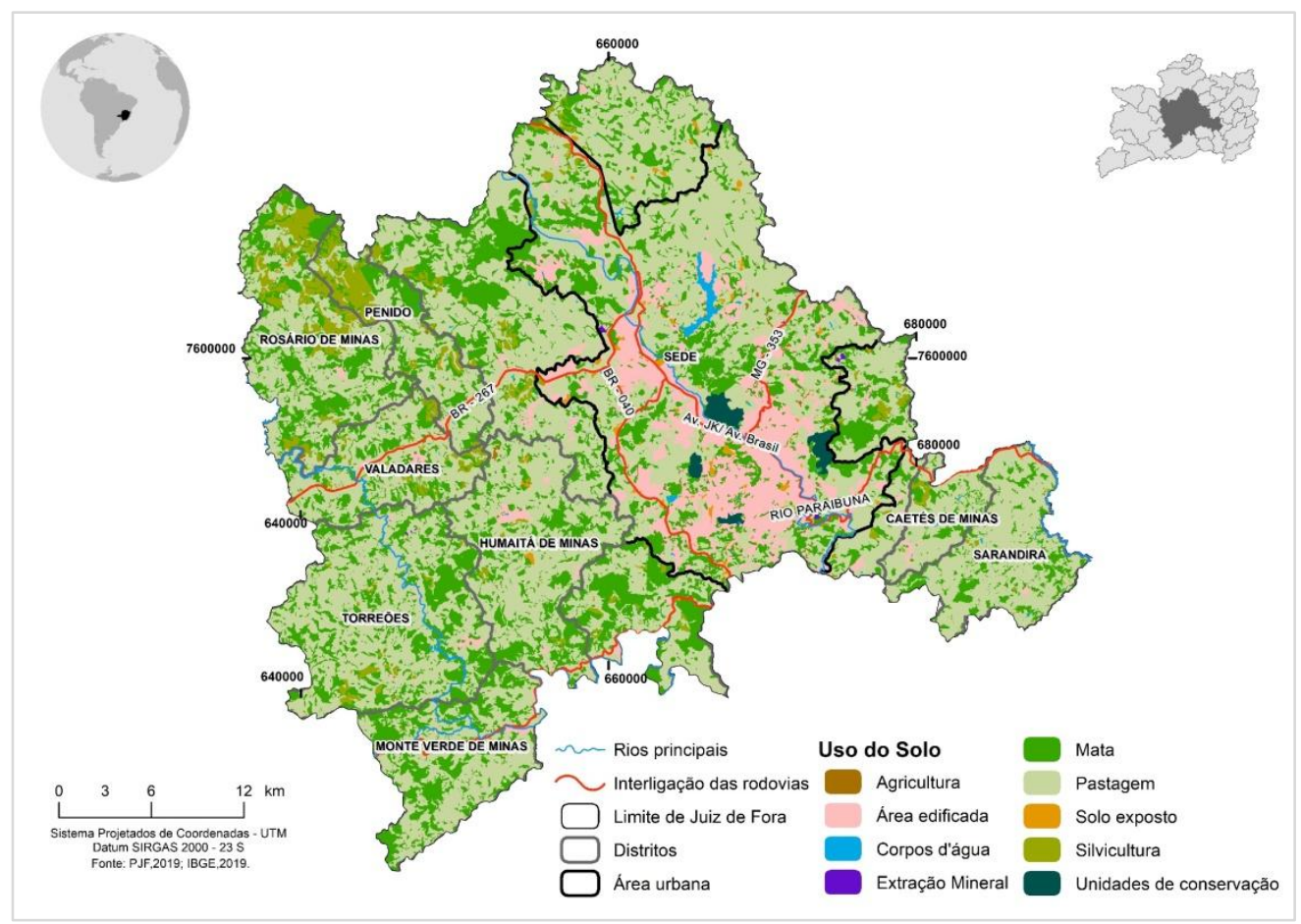

Figura 2 - - Uso e Cobertura da terra em Juiz de Fora. Organizado pelos autores. Fonte: Plano Diretor Participativo, 2016 
De acordo com mapeamento disponibilizado pela Prefeitura de Juiz de Fora, elaborado por PJF(2018), a morfologia de Juiz de Fora caracteriza-se por $38 \%$ de morros, caracterizados por desnivelamento que varia de 100 a 200 m, nos quais encontram-se feições íngremes com topos convexos e, portanto, vales mais encaixados. Em seguida, tem-se com 33\% com feições denominadas de degraus reafeiçoados, que consistem no desnivelamento de 200 a 400 metros, ao que se denomina zonas de transição de compartimentos com diferentes altitudes.

Em menores proporções ainda tem-se as feições: Colinas Suaves e Colinas Íngremes com $6 \%$ do território cada uma, Planície Fluvial e de Terraços ocupando $7 \%$ e $5 \%$, respectivamente. Por fim tem-se os Degraus Escarpados com encostas ingremes, com desníveis acima de 400 m, ocupando 3\% da área do município (figura 3).

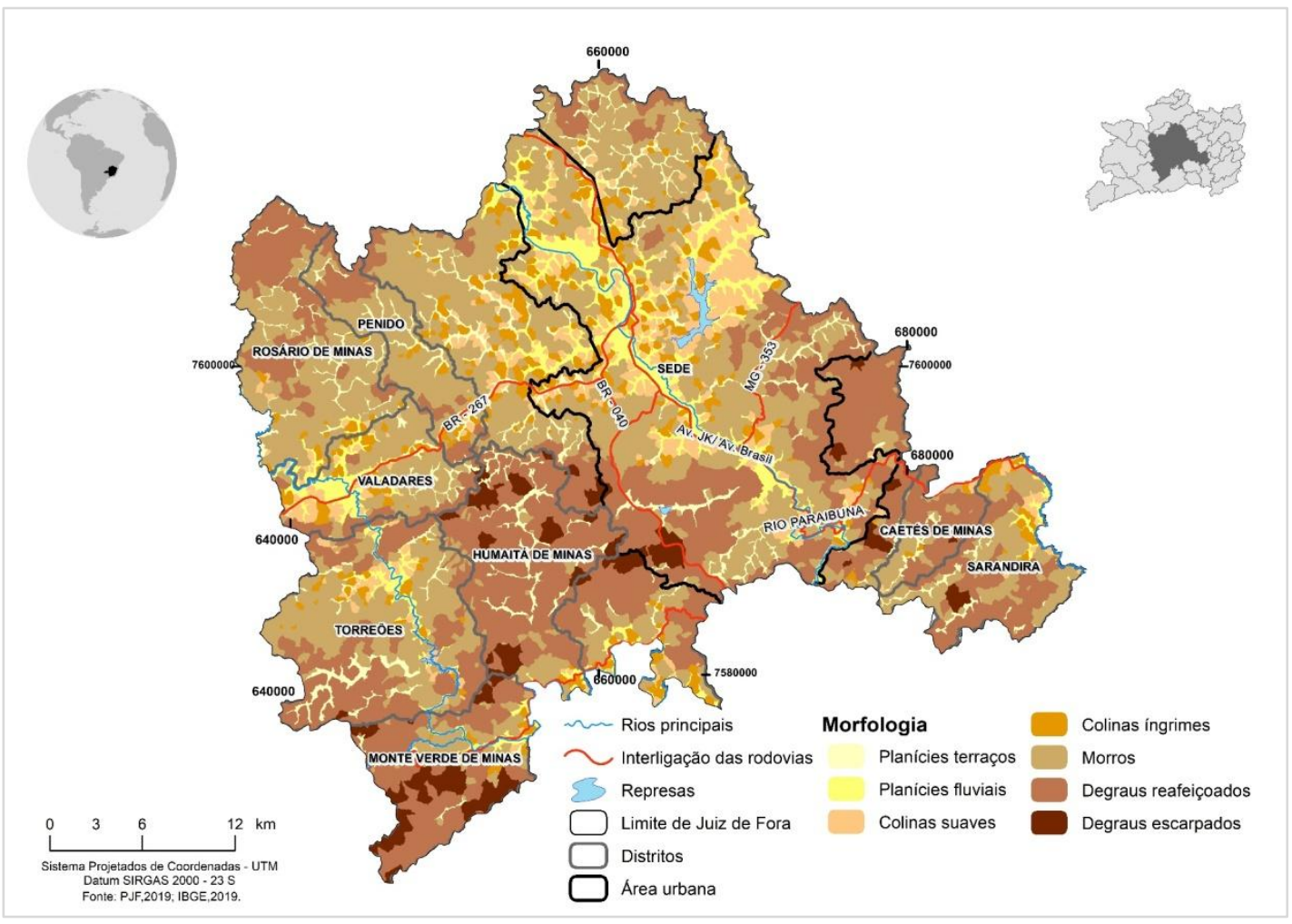

Figura 3 - Mapa de morfologia de Juiz de Fora. Organizado pelos autores. Fonte: PJF,2018.

Segundo TORRES (2006, p.162) "o clima de Juiz de Fora apresenta duas estações bem definidas: uma que vai de outubro a abril, com temperaturas mais elevadas e maiores precipitações pluviométricas, e outra de maio a setembro, mais fria e com menor presença de chuvas". A época das chuvas concentra $83,9 \%$ das precipitações, enquanto a estação seca, 16,1\%.

Conforme Brito (2013), as temperaturas mais elevadas são registradas sob a ação da Massa Tropical Atlântica (MTA) e as mais baixas sob a ação da Massa Polar Atlântica (MPA). De acordo com Neto (2005) e Nimer (1979), sistemas de baixa pressão como os sistemas frontais, provocam situações de instabilidade, acarretando aumento da nebulosidade e precipitação. Ainda pode- 
se observar a atuação da Zona de Convergência do Atlântico Sul (ZCAS) e da Zona de Convergência de Umidade (ZCOU), resultado do estabelecimento de um corredor de umidade com vários sistemas e subsistemas atmosféricos acoplados, caracterizadas por dias seguidos de precipitação no estado de Minas Gerais.

Para caracterização climática geral do municipio foram utilizados dados forcecidos pelas Normais Climátologicas do INMET de 1961-1990 e 1981-2010. A partir dos gráficos presentes na figura 4 é possivel extrair informações a respeito das condições climáticas que o municipio de Juiz de Fora foi exposto no intervalo de 60 anos, sendo o recorte entre 1981 a 1990 de sobreposição entre os dados.

Sobre a temperatura média compensada, observa-se similaridade nos valores dos dois segmentos das Normais, com temperaturas mais elevadas entre Outubro a Abril, com valor ao redor de $19^{\circ} \mathrm{C}$, com pequenas variações nas casas decimais.

A temperatura mínima observada no periodo avaliado, também se distribui durante os meses de maneira similiar à média compensada, sendo o valor mínimo registrado no mês de Julho, com $11,8^{\circ} \mathrm{C}$ na Normal $1961-1990$ e $12,5^{\circ} \mathrm{C}$ em $1981-2010$. Em relação a máxima observa-se valores de $21,8^{\circ} \mathrm{C}$ nos meses de Junho e Julho da Normal 1961-1990 e 22,10 C nos mesmos meses para a normal de 1981-2010. Os valores máximos regitrados ocorrem no mês de fevereiro com $28^{\circ} \mathrm{C}$ e $27,5^{\circ} \mathrm{C}$ de acordo com as nomais de $1961-1990$ e 1981-2010, respectivamente.

A respeito da precipitação, a média do total acumulado variou entre $1597 \mathrm{~mm}$ e $1624 \mathrm{~mm}$ nas normais de 1961-1990 e 1981-2010. Os meses de maiores registros são os de Janeiro e Dezembro e os de menores totais são verificados no mês de Julho, sendo que na normal de 1961-1990 a média do total acumulado nesse mês foi de $23,2 \mathrm{~mm}$ e na normal seguinte foi de 14,1 $\mathrm{mm}$.

A umidade relativa do ar acompanha as variações pluviométricas, porém, é possível observar no gráfico de umidade média compensada que os valores verificados na Normal de 1981-2010 são inferiores aos da Normal anterior. As menores médias detectadas ocorreram em Agosto, em contraposição ao mês de Dezembro com os maiores valores.

Com relação à direção e intensidade dos ventos verifica-se que em Juiz de Fora predominam ventos do quadrante Norte-Nordeste, com velocidade média de $3 \mathrm{~m} / \mathrm{s}$. 


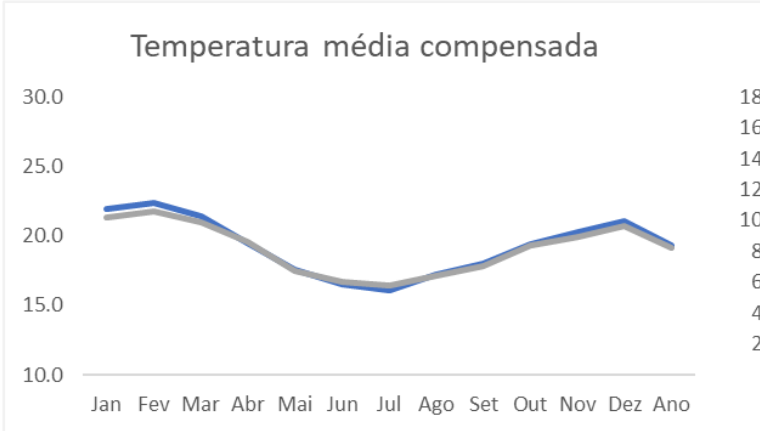

Temperatura mínima

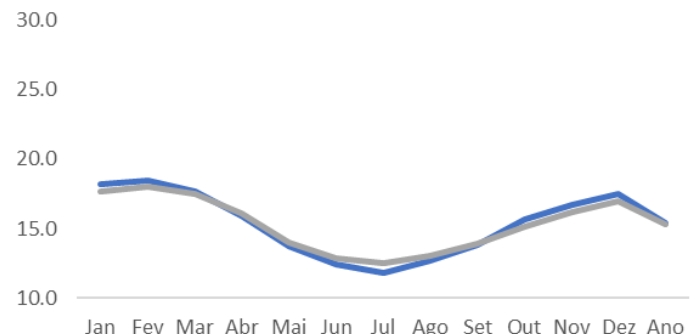

Temperatura máxima

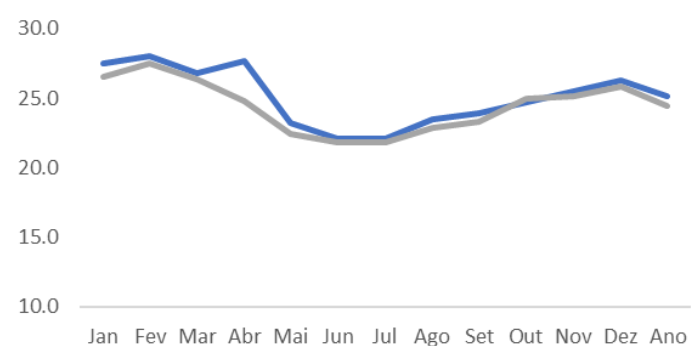

Precipitação acumulada

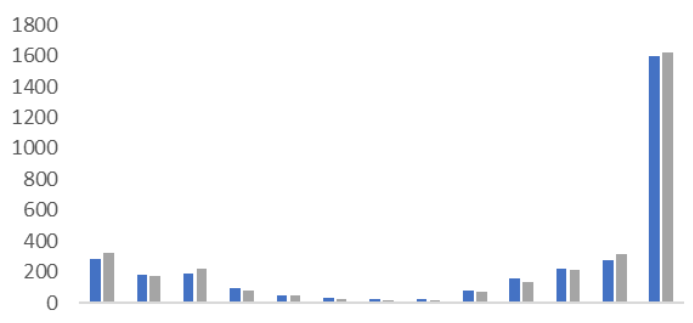

Jan Fev Mar Abr Mai Jun Jul Ago Set Out Nov Dez Ano

Umidade relativa média compensada

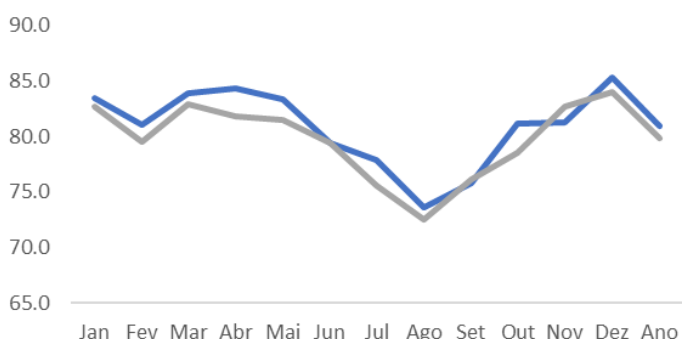

Intensidade e direção do vento

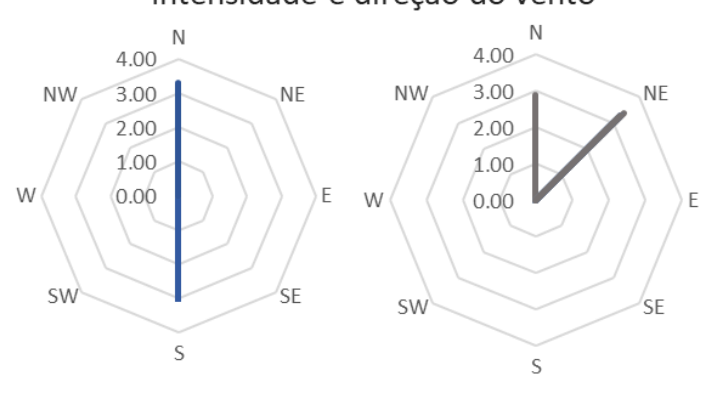

Normais Climatológicas

$1961-1990$

$1981-2010$

Figura 4 - Gráficos dos resultados das Normais Climatológicas. Organizado pelos autores, fonte: INMET.

\section{MATERIAL E MÉTODOS}

Para elaboração desta pesquisa os procedimentos metodológicos foram estruturados em três momentos: revisão teórica, análise das condições térmicas por sensores remotos, aquisição e tratamento de dados em campo, processamento de dados espaciais e, por fim, análise e síntese dos dados.

Com objetivo de uma aproximação inicial das condições de distribuição da temperatura de superfície no município de Juiz de Fora foram utilizadas imagens termais do satélite Landsat 8, fornecido pela Serviço Geológico dos Estados Unidos (USGS) em conjunto com a NASA. No site da agencia foram escolhidas imagens com baixa cobertura de nuvens para os dias que houveram coleta de dados em campo, para que assim os dados de temperatura do ar pudessem ser articulados com a temperatura de superfície. 
A imagem obtida é do dia 19/08/2019, horário no centro da cena 12:51 h. Para elaboração do mapa de temperatura de superfície, utilizou-se a ferramenta de calculadora raster no software ArcGIS versão 10.5. No ambiente do ArcMap, foram adicionadas as bandas 4, 5 e 10 e aplicou-se as seguintes equações:

$$
L \lambda=\mathbf{M} \mathbf{L} * \mathbf{Q} \text { cal }+\mathbf{A} \mathcal{L}
$$

Em que:

$\mathrm{L} \lambda=$ Radiância expectral no topo da atmosfera $\left(\mathrm{W} / \mathrm{m}^{2}\right.$ srd $\left.\mu \mathrm{m}\right)$;

$\mathrm{M}_{\mathrm{L}}=$ Fator multiplicativo de redimensionamento da banda;

$\mathrm{Q}_{\text {cal }}$ Número digital (ND) do pixel;

$A_{L}=$ Fator aditivo reescalonado de radiância para a banda 10 ou $11(0.1)$;

O fator multiplicativo, fator aditivo e constantes de calibração ( $k_{1}$ e $\left.k_{2}\right)$ foram consultados no metadado que acompanha as imagens de satélite. Em seguida calculou-se a temperatura de superfície estimada, com a aplicação da equação:

$$
\operatorname{Trad}=\frac{k 2}{\operatorname{In}\left(\frac{k 1}{L \lambda}+1\right)}
$$

Em que:

$\mathrm{T}_{\mathrm{rad}}=$ Temperatura radiante $(\mathrm{k})$;

$\mathrm{K}_{1}=$ Constante de calibração $(1321,0789)$;

$\mathrm{K}_{2}=$ Constante de calibração $(774,8853)$;

Em seguida é feita a conversão da temperatura de Kelvin para Celsius e classificação do mapa.

Para entender a relação entre os componentes da paisagem e a temperatura de superfície, utilizou-se a ferramenta de estatística zonal do QGIS versão 3.6. Para execução da mesma foi gerado um grid com células de 30 metros (30x30) para toda superfície do município, com a ferramenta "criar grade". Em seguida, aplicou-se a ferramenta de estatística zonal cruzando o vetor do grid com os rasters de altimetria, orientação de vertentes, morfologia, uso do solo e temperatura da superfície. Nestes, as estatísticas calculadas foram contagem, média, moda, mínima e máxima.

Para as variáveis de distribuição contínua, utilizaram-se os valores médios e para as variáveis categóricas como uso do solo e morfologia, foram feitos os cálculos de área de cada categoria do mapa por célula da grade. As áreas foram calculadas através da ferramenta histograma zonal no QGIS 3.6, o qual calcula um número de pixels de cada categoria por quadrante. De posse da quantidade de pixels, aferiu-se a área através da multiplicação do número de pixels pelo tamanho das células que nesse caso é de 0,9 hectares. 
Após os cálculos as tabelas foram inseridas no banco de dados PostgreSQL, uma vez que se tratava de um grande número de células de difícil operação em outras ferramentas. Assim, depois de inseridas as tabelas, calculou-se a o coeficiente de correlação de Person entre cada uma das variáveis e a temperatura de superfície.

Como resultado encontrou-se diferentes valores de correlação, muitos pouco significativos, o que já era de certa forma esperado, uma vez que determinadas variáveis guardam maiores relações com a temperatura do ar e não diretamente com a temperatura de superfície. Porém, através dos resultados, foi possível verificar as categorias de maior influência com a temperatura de superfície.

Para homogeneização das condições de mensuração e de coleta dos dados em campo utilizou-se o modelo de abrigo meteorológico proposto por Jardim (2018), com condições de resistir ao monitoramento contínuo durante os 70 dias de coleta conforme a figura 4.

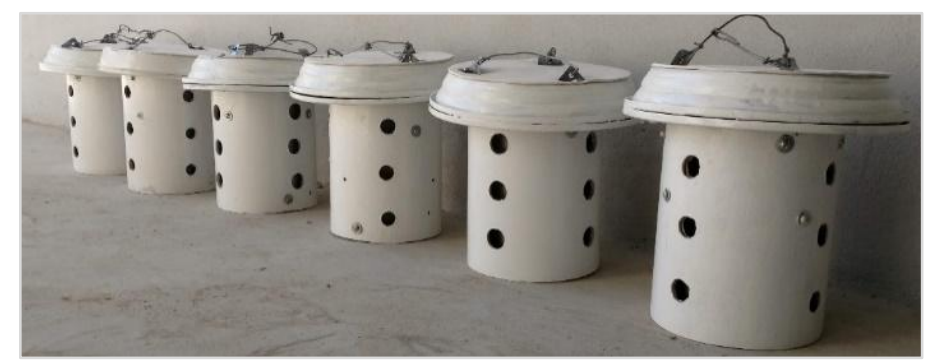

Figura 5 - Abrigos meteorológicos utilizados em campo. Fonte: Organizado pelos autores.

A escolha dos pontos de controle em campo baseou-se na disponibilidade de locais possíveis para instalação do equipamento em segurança, além da melhor distribuição espacial viável, em diferentes condições de uso e ocupação do solo. Dessa forma foram distribuídos 6 pontos de controle pelo município de Juiz de Fora, com 4 pontos instalados dentro do perímetro urbano e 2 pontos em área rural. Entende-se como ponto de controle, local onde foram instalados os abrigos em campo.

O primeiro ponto instalado (Ponto 1 ) encontrava-se junto à estação meteorológica do INMET para que os equipamentos utilizados pudessem ser aferidos e corrigidos com dados oficiais. Dos pontos em área rural um deles foi alocado em área de pastagem (Ponto 2) e outro em mata ciliar (Ponto 3), na busca de retratar duas situações comuns da zona rural juiz-forana. Nos pontos alocados na área urbana priorizou-se diferentes tipos de ocupação na cidade, sendo destacadas condições dominadas por uso residencial próximas a área central. O ponto 4 localizava-se em um bairro com edificações mais espaçadas de uso residencial e lazer circundada de fragmentos de vegetação e pastagens. 0 ponto 5 encontrava-se no bairro Progresso, com perfil essencialmente residencial e diversas habitações com características de autoconstrução. Por fim, o ponto 6 situava-se em bairro distante da região urbana central, porém, relevante para o município, uma vez que se tratava da região industrial. Nesse ponto o abrigo foi alocado no pátio de uma empresa que se dispôs a auxiliar nesse monitoramento. Os pontos de controle podem ser visualizados na figura 5 . 


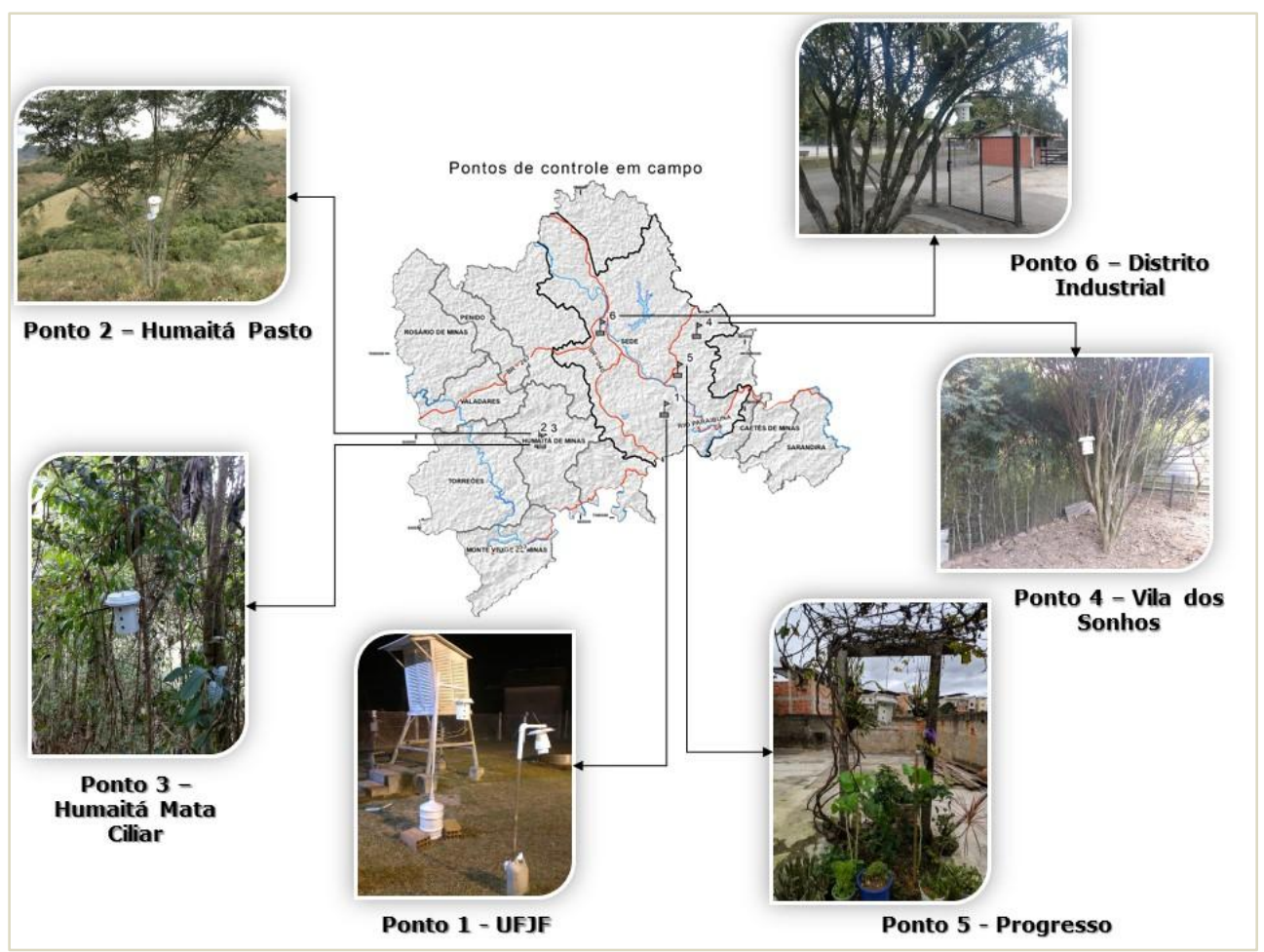

Figura 6 - Identificação dos pontos de controle. Organizado pelos autores..

O equipamento acoplado aos abrigos consiste em unidades Datalogger de Temperatura e Umidade - modelo HT-500, da marca Instrutherm conforme figura 7. Os abrigos foram instalados, obedecendo distância 1,5 $\mathrm{m}$ da superfície do solo. Quando haviam condições de instalação direta do abrigo, assim foi feito e, quando não, utilizou-se um suporte confeccionado para essa finalidade, cumprindo a mesma condição de distância da superfície e com a utilização de materiais brancos ou pintados com mesma cor.

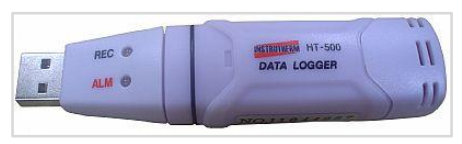

Figura 7 - Datalogger HT-500, Intrutherm. Fonte: site do fabricante.

O monitoramento iniciou-se no dia 19 de julho de 2019, mas a instalação de todos os pontos foi concluída no dia 22 do mesmo mês, dessa forma eliminou-se os dados dos dias em que não houve monitoramento em todos os pontos, além da supressão do primeiro e último dia de coleta simultânea, para evitar ruídos e padronizar o procedimento. O datalogger foi programado para registros com intervalos de 60 minutos, continuamente, por 71 dias. Ao fim desse período os dados foram coletados e armazenados. As condições gerais dos pontos de controle podem ser observadas na tabela 1 , a seguir: 
Tabela 1 - Descrição dos pontos de controle.

\begin{tabular}{|c|c|c|c|c|c|c|c|}
\hline \multicolumn{8}{|c|}{ Descrição dos Pontos de Controle } \\
\hline Ponto & Nome & Localidade & Tipo & Lat & Long & $\begin{array}{c}\text { Altitude } \\
\text { (m) }\end{array}$ & Instalação \\
\hline 1 & UFJF & $\begin{array}{l}\text { Estação } \\
\text { Meteorológica do } \\
\text { INMET, bairro } \\
\text { Martelos }\end{array}$ & Urbano & -21.76 & -43.36 & 940 & $17 / 07 / 2019$ \\
\hline 2 & $\begin{array}{l}\text { Humaitá } \\
\text { Pasto }\end{array}$ & $\begin{array}{l}\text { Sítio Mendes, } \\
\text { distrito de } \\
\text { Humaitá }\end{array}$ & Rural & -21.8 & -43.51 & 796 & $18 / 07 / 2019$ \\
\hline 3 & $\begin{array}{l}\text { Humaitá } \\
\text { Mata Ciliar }\end{array}$ & $\begin{array}{l}\text { Sítio Mendes, } \\
\text { distrito de } \\
\text { Humaitá }\end{array}$ & Rural & -21.8 & -43.5 & 686 & $18 / 07 / 2019$ \\
\hline 4 & $\begin{array}{l}\text { Vila dos } \\
\text { Sonhos }\end{array}$ & $\begin{array}{l}\text { Rua Diomar } \\
\text { Monteiro, n630, } \\
\text { bairro Vila dos } \\
\text { Sonhos }\end{array}$ & Urbano & -21.68 & -43.32 & 793 & $18 / 07 / 2019$ \\
\hline 5 & Progresso & $\begin{array}{l}\text { Rua da Passagem, } \\
\mathrm{n}^{\circ} 86, \text { bairro } \\
\text { Progresso }\end{array}$ & Urbano & -21.72 & -43.34 & 759 & $18 / 07 / 2019$ \\
\hline 6 & $\begin{array}{l}\text { Distrito } \\
\text { Industrial }\end{array}$ & $\begin{array}{l}\text { Ra Antônio Simão } \\
\text { Firjam, n²40, } \\
\text { bairro Distrito } \\
\text { Industrial }\end{array}$ & Urbano & -21.68 & -43.44 & 686 & $22 / 07 / 2019$ \\
\hline
\end{tabular}

Fonte: elaborado pela autora.

Para aferição um modelo de cada datalogger utilizado no monitoramento foi instalado junto a estação meteorológica do INMET de Juiz de Fora, durante todo período de coleta. Após a coleta dos dados em campo, os mesmos foram organizados e convertidos para o formato xlsx. Em seguida, fez-se o cálculo das diferenças entre o dado registrado nos dataloggers e na estação do INMET e calculou-se a média horária para todos os dias de monitoramento, aplicada, posteriormente, no ajuste dos dataloggers para todos os pontos de coleta.

Após aferição e correção, aplicaram-se recursos básicos de estatística com cálculos de máxima, mínima e média para toda a série. Esse mesmo procedimento foi aplicado, em seguida, aos dados organizados em sequências horárias de 24 horas, donde se extraiu os valores médios, máximos e mínimos.

Com os dados tratados foi possível identificar zonas homogêneas partindo dos valores de temperatura média por ponto de controle, utilizando-se dos interpoladores espaciais, com testes de diferentes métodos que já foram utilizados em outras pesquisas de análises climáticas. Dessa forma foram testados quatro métodos de interpolação: Inverso quadrado da distância (IDW), Krigagem, Função da base radial (RBF) e Polinômio local (LPI), todos esses presentes no software ArcGIS versão 10.6.

O primeiro interpolador testado foi o IDW que calcula os valores de células a partir da combinação ponderada linearmente, em função da distância inversa dos valores, nos pontos de amostra. Em seguida foi testada a Krigagem que estima a distribuição dos valores de célula através da ponderação da distância entre os pontos medidos e a localização da previsão, além do arranjo espacial geral dos pontos medidos (ESRI,2019).

O RBF, outro método utilizado, consiste em técnica de interpolação exata, em que a superfície passa por cada valor medido da amostra. Esse método é utilizado para produzir superfícies suaves a partir de grande número 
de pontos de dados. Por fim, testou-se o Polinômio Local, o qual atribui valores de referência a "nós" dentro de uma vizinhança predefinida. Nesse caso os dados observados mais próximos do nó obtêm maior peso nos cálculos, e nos mais distantes, menores pesos.

Entretanto os resultados apresentaram limitações, uma vez que a distribuição dos valores de temperatura, mostraram distorções nos casos em que havia dois pontos com maior proximidade, como no caso do Ponto 2 e 3 . Diante dos resultados obtidos, observou-se que o raster resultante do interpolador IDW foi o mais próximo da realidade de distribuição térmica do município. Assim, adotou-se o produto desse interpolador como zoneamento térmico da área de estudo. Os parâmetros adotados para aplicação do interpolador foram estabelecidos no default da ferramenta, sendo o raio de busca variável, com 12 pontos de amostras de entradas mais próximas a serem utilizadas para executar a interpolação em uma distância máxima de 60 km, que consiste da diagonal do perímetro do município.

Posteriormente ao tratamento dos dados climáticos, partiu-se para o processamento de dados espaciais atrelados aos aspectos do meio físico que possuem relação com o balanço de radiação e, por sua vez, com a temperatura. Dessa forma seguiu-se na confecção e análise de material cartográfico de uso e cobertura do solo e morfologia do relevo, sendo que para elaboração dos mesmos utilizou-se da base de dados cedidas pela Prefeitura de Juiz de Fora.

Na confecção dos layouts fez-se uso de técnicas de geoprocessamento e cartografia digital operadas no software ArcGis 10.6 e QGIS 3.6. Para elaboração dos mapas de localização da área de estudo, uso do solo e morfologia do relevo fez-se uso das bases de dados constantes da tabela 2.

Tabela 2 - Fonte de dados utilizadas na elaboração dos layouts.

Dados espaciais e tabulares fornecidos pela

Prefeitura de Juiz de Fora

\begin{tabular}{|c|c|c|c|c|c|}
\hline Tema & Descrição & Tipo & Escala/Resolução & Data & Fonte \\
\hline Hidrografia & $\begin{array}{l}\text { Rede Hidrográfica com rios } \\
\text { principais e secundários }\end{array}$ & Vetor & Não informado & 2014 & SEPLAG - PJF \\
\hline Uso da Terra & $\begin{array}{l}\text { Uso e cobertura da terra } \\
\text { do município de Juiz de } \\
\text { Fora }\end{array}$ & Vetor & Não informado & 2014 & SEPLAG - PJF \\
\hline Hipsometria & $\begin{array}{l}\text { Modelo digital de elevação } \\
\text { com resolução espacial de } \\
5 \text { metros }\end{array}$ & Matricial & 5 metros & 2014 & SEPLAG - PJF \\
\hline Morfologia & $\begin{array}{l}\text { Layer de feições } \\
\text { morfológicas do município } \\
\text { de Juiz de Fora }\end{array}$ & Vetor & Não informado & 2014 & SEPLAG - PJF \\
\hline
\end{tabular}

Como análise de síntese dos dados coletados em campo e aspectos de uso do solo e relevo, foi construído um esboço do traçado de unidades topoclimáticas, resgatando a base de uso e cobertura do solo e morfologia.

Destaca-se a escolha do mapeamento de morfologia, uma vez que essa classificação agrega aspectos de altimetria e declividade, a partir da metodologia proposta por Silva (2002), em que considera os desnivelamentos altimétricos com adaptações das feições agradacionais. O mapa morfológico utilizado possui 7 classes, sendo essas: planícies terraços, planícies fluviais, 
colinas suaves, colinas íngremes, morros, degraus reafeiçoados e degraus escarpados.

A ideia para delimitação do esboço das unidades climáticas partiu da identificação das categorias presentes em cada porção do município. Para isso fez-se o uso das estatísticas zonais calculadas para a grade de 500×500 m sobre o município juiz-forano, sendo utilizado os valores de moda para os mapas categóricos de Morfologia e Uso do Solo e média para o mapa interpolado de temperatura média.

Destaca-se que esse esboço de unidades não se trata de uma análise de multicritério, portanto, não foram estabelecidos pesos para as categorias analisadas, as mesmas não foram sequer somadas. Essa proposta metodológica teve como objetivo identificar os agrupamentos formados pela combinação dos três aspectos considerados, os quais se constituem em um primeiro esboço das possíveis unidades climáticas formadas.

Com a tabela resultante das estatísticas zonais os dados foram inseridos no banco de dados PostgresSQL. Em seguida foi realizada a reclassificação das categorias consideradas em 5 classes e para resultados de morfologia agruparam-se as classes de colinas suaves e colinas íngremes, além das classes de degraus reafeiçoados e degraus escarpados, totalizando 5 classes.

O mapa de uso também foi recategorizado em 5 classes, considerando as categorias que possuem comportamento térmico similar: UC's a Mata Nativa, Silvicultura a Agricultura, Extração Mineral, Área Edificada e Solo Exposto. Já as classes pastagem e cursos d'água foram mantidas separadas.

Com o objetivo de padronizar as categorias analisadas, o mapa interpolado de temperatura também foi categorizado em 5 classes: 16,0$16,5^{\circ} \mathrm{C} ; 16,5-17^{\circ} \mathrm{C} ; 17-17,5^{\circ} \mathrm{C} ; 17,5-18^{\circ} \mathrm{C} ; 18-18,6^{\circ} \mathrm{C}$. Foram estabelecidos os intervalos de $0,5^{\circ} \mathrm{C}$, uma vez que o maior detalhamento dos intervalos contribuiria para o aumento do numero de combinação das classes dificultando o processo de generalização dos agrupamentos. Pretende-se no decorrer da pesquisa diminuir os intervalos para identificação com maior detalhamento das unidades, porém esse não foi o objetivo desse artigo.

Assim foi consolidada uma tabela com atributos de geometria, uso do solo, morfologia e temperatura, sendo a classe de cada categoria de analise identificada por um valor de 1 a 5, por quadricula do grid. Em seguida foi criado um código concatenado de três dígitos, composto pelo primeiro dígito do código que corresponde à temperatura média, o segundo atrelado ao uso do solo e o último associado à classe de morfologia do relevo. Os valores de cada classe das categorias analisadas podem ser visualizados na figura 8.

Depois dos códigos formados, cada quadricula apresentava sua combinação de categorias analisadas, sendo possível verificar 70 combinações ocorridas. Em seguida, agruparam-se as geometrias com combinações iguais a partir de consulta em linguagem SQL, com uso das funções de GROUP BY e ST_UNION.

Com as feições de mesmo código unidas, extraiu-se a tabela com geometria do banco e assim inseridas no ambiente do ArcMap, local onde o layout do mapa foi gerado. Com objetivo de agrupar ainda mais o número de classes e reduzir os ruídos na visualização dos padrões das zonas de 
comportamento semelhante, foi feita a reclassificação de todas as geometrias formadas por menos de 10 quadrantes. A esses casos foram atribuídos o código 999, reduzindo-se a 34 combinações distintas.

Com as combinações restantes confeccionou-se o mapa de esboço de unidades climáticas, devido à relevância da categoria temperatura, definindo-se então como aspecto principal de caraterística da unidade. Sendo assim, atribuiuse a mesma cor para as combinações dentro da mesma faixa de temperatura, sendo as variações de tonalidade utilizada para identificar as variações de combinação referentes ao relevo e uso do solo. Os procedimentos realizados na confecção das unidades podem ser visualizados na figura 8 .

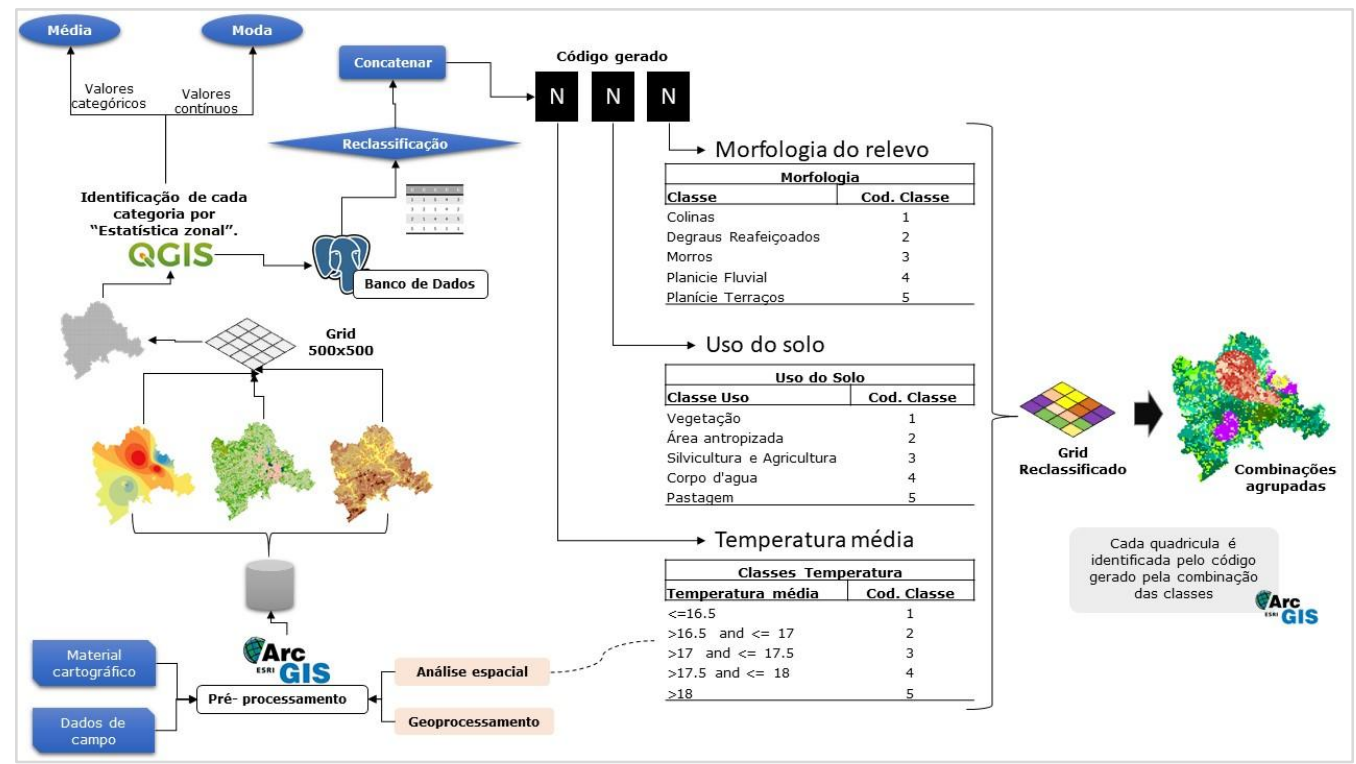

Figura 8 - Procedimentos para elaboração o esboço de unidades topo climáticas. Organizado pelos autores.

\section{RESULTADOS E DISCUSSÃO}

O primeiro resultado obtido foi o mapeamento de temperatura de superfície do município (figura 9) para o dia 19 de agosto de 2019. A partir desse mapa foi possível observar a amplitude da temperatura de $21^{\circ} \mathrm{C}$, com mínima de $12^{\circ} \mathrm{C}$, máxima de $33,9^{\circ} \mathrm{C}$ e média de $19,5^{\circ} \mathrm{C}$.

Sobre a distribuição verifica-se que a porção no leste do município registrou menores valores, resultados justificados possivelmente pela presença de fragmentos de vegetação e corpos d'agua observados no mapa de uso do solo. Na faixa oeste têm-se representativa presença de áreas de pastagem, combinadas com solo exposto, os quais apresentam maior absorção de radiação e por isso podem revelar temperaturas mais elevadas.

Diferentemente daquilo que era esperado área urbana possui valor médio de temperatura inferior àquela observada na extensão rural, com valores médios de $19,0^{\circ} \mathrm{C}$ e $19,6^{\circ} \mathrm{C}$, respectivamente. A temperatura máxima na área urbana foi de $30,5^{\circ} \mathrm{C}$ e na área rural o valor registrado foi de $33,9^{\circ} \mathrm{C}$. Com relação às mínimas os valores foram de $12^{\circ} \mathrm{C}$ no urbano e $13,9^{\circ} \mathrm{C}$ no rural. Esses resultados revelam o papel determinante do uso do solo relativo à 
pastagem, o qual ocupa cerca de $60 \%$ do território municipal, sendo a maior parte desse percentual nas áreas rurais.

Outra questão interessante a ser observada nesse mapa refere-se à região situada no extremo noroeste do município. No distrito de Rosário de Minas, onde se verificam concentração de temperaturas mais baixas com valor mínimo de $15.7^{\circ} \mathrm{C}$ e máxima de $26.0^{\circ} \mathrm{C}$, possivelmente justificada pela significativa presença do uso silvicultura. Porém, é valido destacar que mesmo se tratando de gêneros florestais, o comportamento é diferenciado quando comparado a áreas de mata. Portanto, é possível afirmar que os tipos vegetacionais atrelados à silvicultura não possuem o mesmo potencial de arrefecimento da temperatura de superfície.

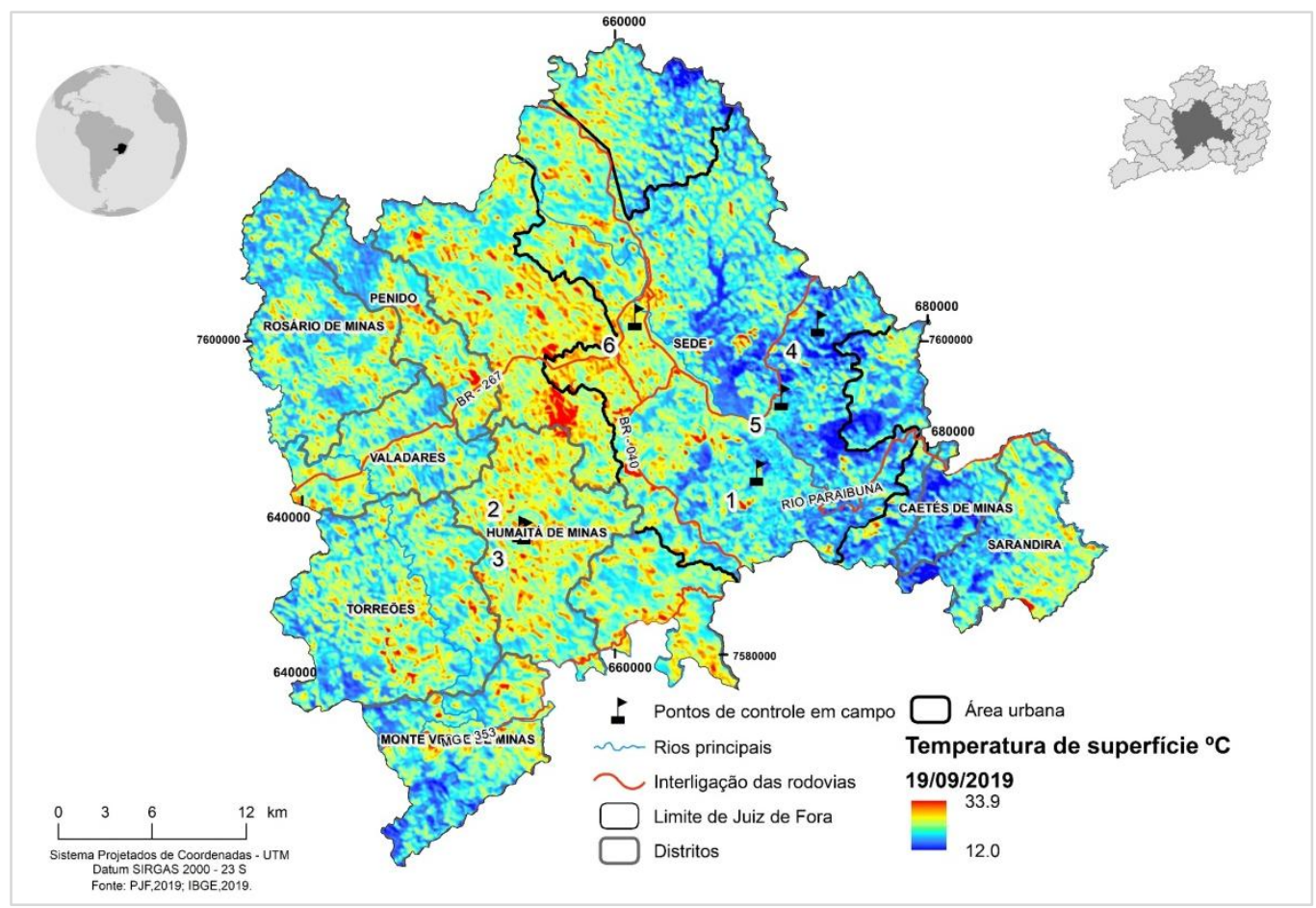

Figura 9 - Mapa de temperatura de superfície de Juiz de Fora- MG. Organizado pelos autores.

Com relação aos dados coletados em campo, o ponto com menor temperatura média foi o alocado na zona rural em fragmento de mata ciliar (Ponto 3) com $16,4^{\circ} \mathrm{C}$. Outro ponto com comportamento similar foi o ponto 4, na Vila dos Sonhos com $16,5^{\circ} \mathrm{C}$ (Figura 10 - Gráfico A). O mesmo padrão também foi visualizado com relação às mínimas, nos pontos 3 e 4, com as temperaturas em $3,7^{\circ} \mathrm{C}$ e $4,1^{\circ} \mathrm{C}$, respectivamente (Gráfico C). Sobre esses pontos também é importante destacar que os mesmos se apresentaram com os maiores registros de umidade relativa média, o ponto $3 \mathrm{com} 80,4 \%$ e o ponto 4 com $78,3 \%$ (Gráfico D). Essas respostas mostram a influência exercida pela presença de corpos hídricos nas proximidades, cuja evaporação retira parte do calor sensível do ambiente (convertido em calor latente), reduzindo as variações de temperatura extremas diurnas e estacionais. É dessa forma que grandes massas de água atuam de maneira a estabilizar os valores de temperatura, reduzindo as amplitudes térmicas (ROMERO, 1998). 
Sobre a temperatura máxima registrada durante o período de coleta de dados, verifica-se que o ponto de controle 6 , localizado no Distrito industrial, possui a temperatura máxima mais elevada de $35,4^{\circ} \mathrm{C}$ (Gráfico $\mathrm{C}$ ). Esse ponto também possui a temperatura média mais alta de $18,7^{\circ} \mathrm{C}$. O ponto de controle 5, no bairro Progresso, possui comportamento semelhante com alto valor de temperatura máxima $\left(34,2^{\circ} \mathrm{C}\right)$. O que diferencia os dois pontos é a amplitude térmica, maior no Distrito industrial quando comparada ao ponto 4 . 0 comportamento térmico desse ponto pode estar relacionado às características de uso e cobertura do solo, uma vez que os dois são os únicos pontos alocados em áreas completamente pavimentadas.

Outra questão relevante a ser apresentada está no fato do ponto 5 estar mais próximo a área mais adensada do município, o que possivelmente corroborou para o maior armazenamento do calor, diminuindo as amplitudes térmicas existentes. A área do entorno do ponto 6 consiste em áreas pavimentadas e impermeabilizadas, intercaladas com áreas de vegetação rasteira, contribuindo para redução do calor acumulado. Uma vez que o tecido vegetal não é bom transmissor e nem armazenador de calor, além do acionamento do mecanismo de evapotranspiração, por meio do qual a planta regula suas variações de temperatura. Essas questões podem ser melhor visualizada na figura 10.

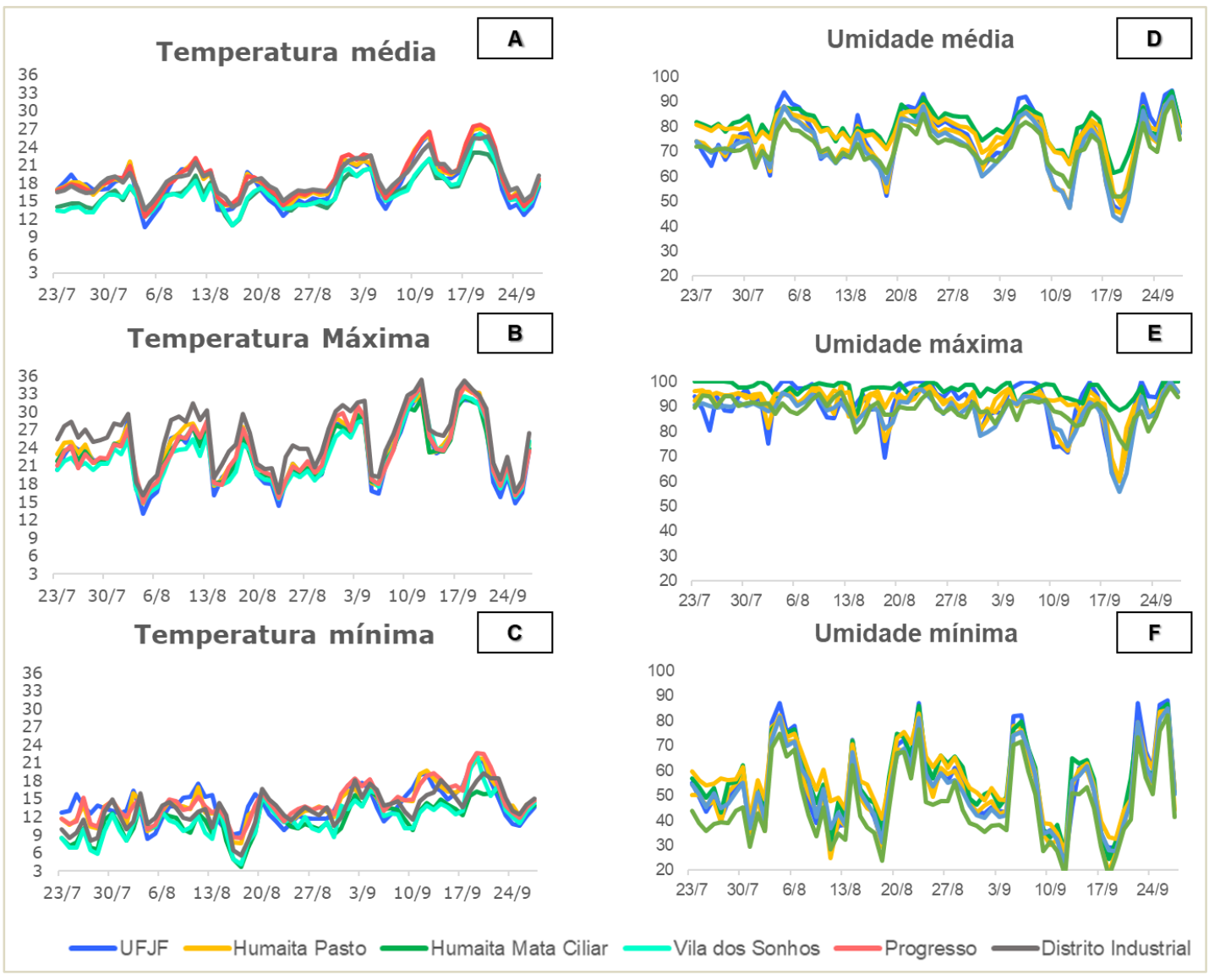

Figura 10 - Gráficos de Temperatura e Umidade média, máxima e mínima. Organizado pelos autores. 
Temperatura nos pontos de controle

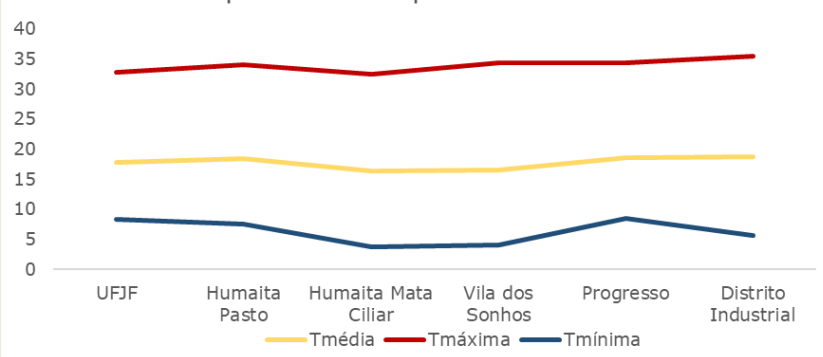

Figura 11 - Estatísticas básicas dos pontos de controle, média, máxima e mínima. Organizado pelos autores.

Ainda sobre os resultados de campo, destaca-se a realidade revelada pelo ponto de controle 2, instalado em área de pastagem, que apesar de estar em área rural rodeada por fragmentos de vegetação, também apresentou elevados valores de temperatura máximas, mínimas e médias, com valores de $34^{\circ} \mathrm{C}, 7,5^{\circ} \mathrm{C}$ e $18,4^{\circ} \mathrm{C}$, desempenho térmico similar a uma área completamente urbanizada como o bairro Progresso, fato também observado por Jardim e Moura (2018) em estudo comparativo da área urbana e rural de Januária, norte de Minas Gerais.

Embora a constatação desse fato exija período maior de monitoramento, variando as condições de tempo meteorológico no decorrer das estações do ano, o papel atribuído à vegetação como controle de variação da temperatura do ar deve ser visto com cautela, atento à dimensão e características da vegetação. Em artigo recente, Jardim e Galvani (2018) verificaram valores de temperatura do ar significativamente mais elevados em área de cerrado no interior do Parque Nacional da Serra do Cipó do que aqueles da área urbana de Belo Horizonte, principalmente nos horários mais quentes do dia. Diferente do interior do ambiente de mata ciliar, com valores de temperatura sempre mais baixos durante o dia e sensivelmente maiores no período noturno.

Em primeiro deve-se destacar que elevados valores de temperatura não se constituem em fator limitante para grande parte das plantas tropicais, desde que tenham atendidas suas necessidades hídricas. E no caso da vegetação de cerrado, com elementos arbóreos esparsos e predomínio de estrato herbáceoarbustivo, a produção de calor sensível é elevada sendo transferida rapidamente para o ar, uma vez que o tecido vegetal é péssimo transmissor e armazenador de calor (conforme foi discutido anteriormente) e pelo fato da cobertura foliar não impedir a entrada de radiação direta como ocorre na mata ciliar. Na verdade, o emaranhado de folhas e galhos ampliam a área de recepção de radiação solar e, portanto, de superfícies sujeita ao aquecimento e transferência de calor para o ar (JARDIM e GALVANI, 2018).

A respeito da distribuição horária da temperatura do ar, é possível visualizar no gráfico $B$, da figura 12 , como os pontos aquecem de maneira distintas, visto que os pontos da Vila dos Sonhos, Humaitá e Mata Ciliar se apresentam com temperaturas inferiores nos primeiros momentos da manhã por volta de 5 e 6 horas. Essa observação revela as características dos elementos que constituem essas áreas, com valor de calor especifico mais elevado e, assim, levando mais tempo para elevar a temperatura. 
Outro fato a ser observado na figura 12 é de como o ponto 3, por ser tratar de área coberta de vegetação, perde calor com maior rapidez, que é possível de visualizar no gráfico C, quando, após 16h, apresenta redução significativa da temperatura do ar. Além disso, há de se destacar que o comportamento do ponto do distrito industrial demora para atingir o pico da temperatura máxima, mas, por outro lado, mostra rápida redução de seus valores, como é possível ver no gráfico $\mathrm{C}$.

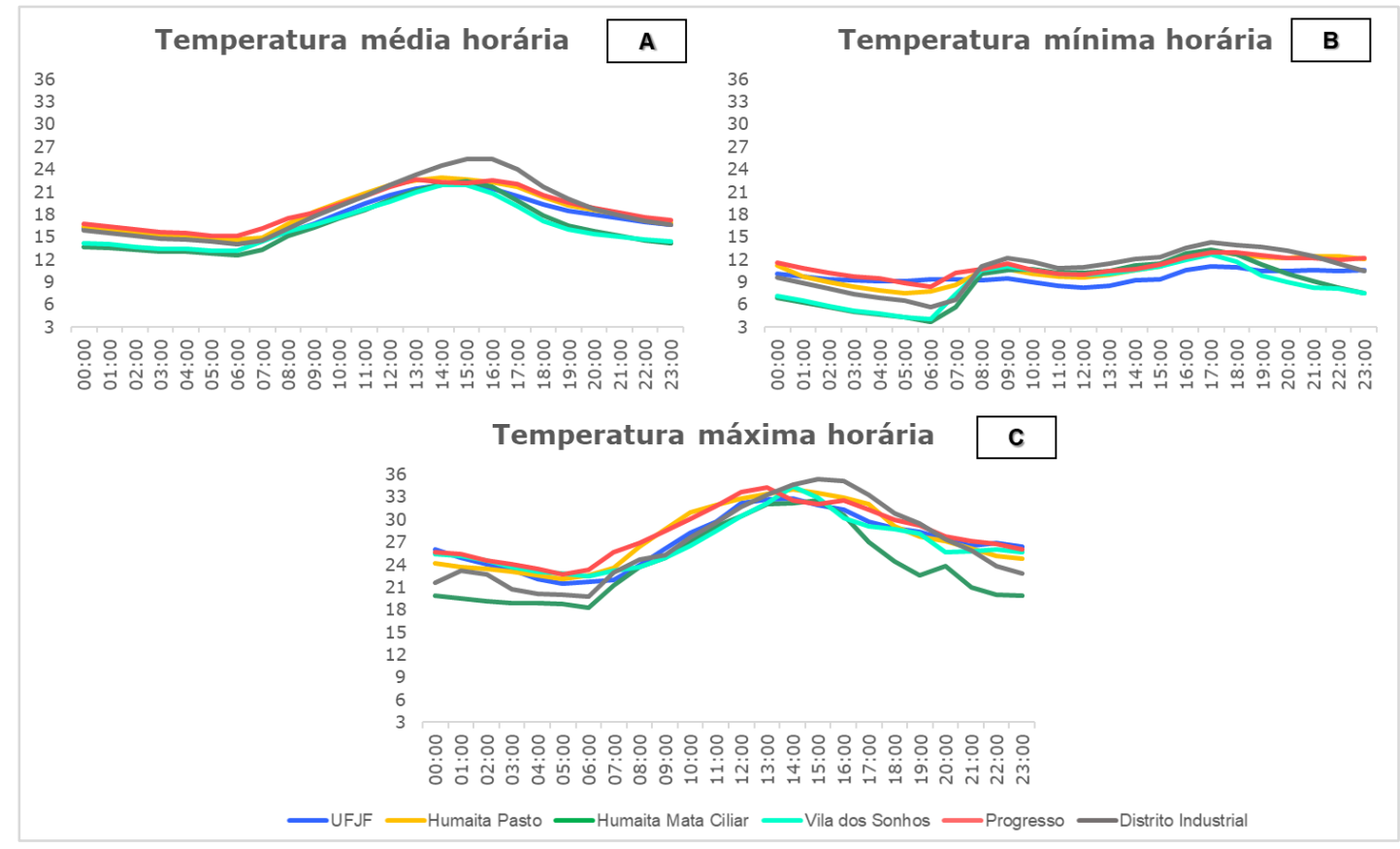

Figura 12 - Gráficos de distribuição horaria da temperatura. Organizado pelos autores.

Para visualizar os dados monitorados em campo, distribuídos de maneira a cobrir áreas em que não houveram coletas, fez-se uso de técnicas de análises espaciais como a interpolação dos valores de temperatura média, cujo produto pode ser visualizado na figura 13. 


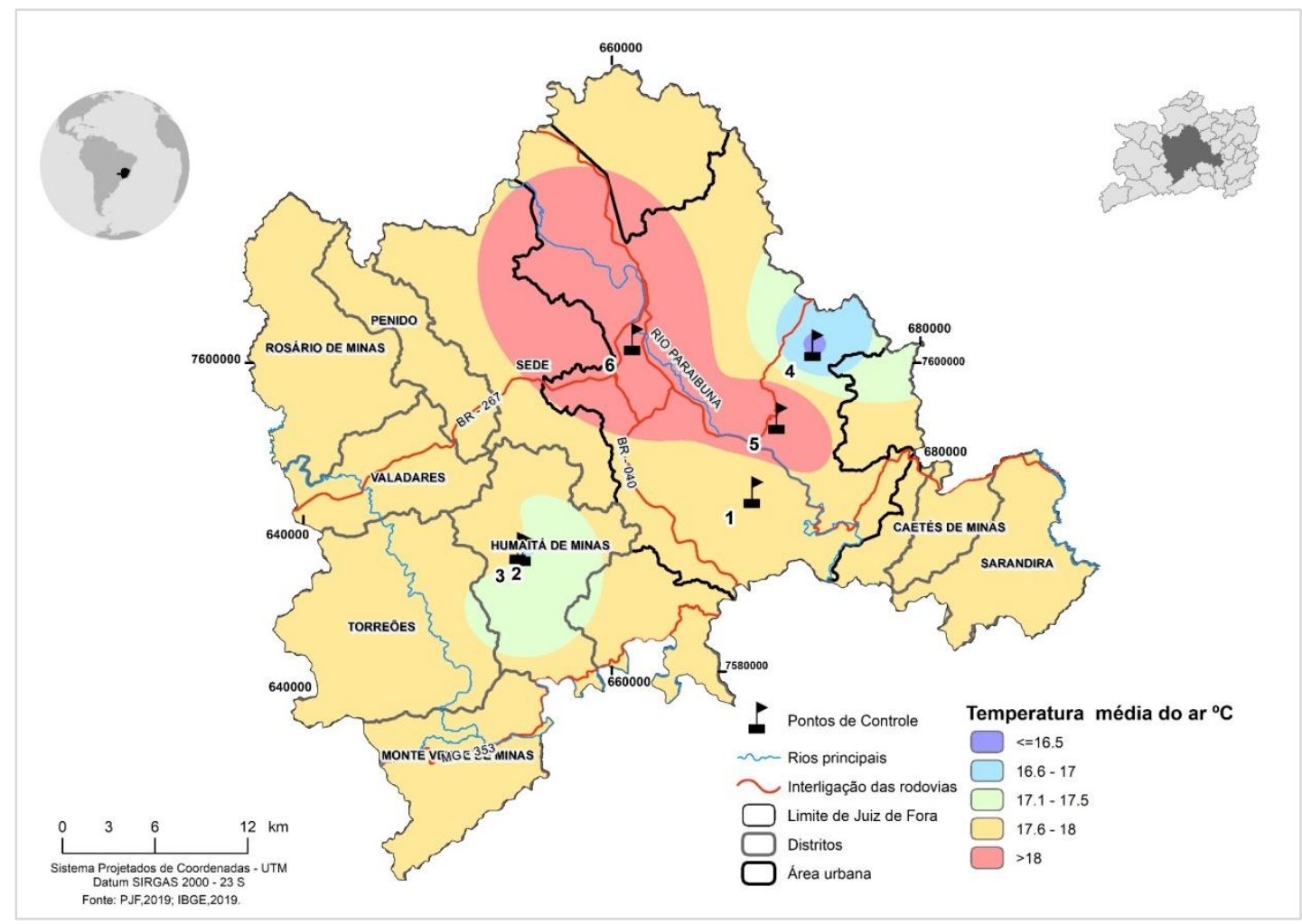

Figura 13 - Temperatura média do ar em Juiz de Fora, para os meses entre julho e setembro de 2019. Organizado pelos autores.

Através do mapa anterior (figura 13) foi possível visualizar a formação de 2 unidades, uma representada em vermelho que incorpora os pontos de controle 4 e 6 , apontados anteriormente como pontos com temperaturas mais elevadas. Uma questão de destaque está, também, no ponto 1 , alocado na estação meteorológica do INMET e que, apesar de estar em altitude mais elevada, sendo caracterizada no mapa morfológico como Degraus Reafeiçoados, o fator altimétrico é pouco expressivo, uma vez que o entorno dessa área, atualmente, é densamente urbanizado, indicada como zona de expansão pelo novo plano diretor.

Além disso, observa-se, também, duas áreas com valores de temperaturas menos elevadas, localizadas em áreas mais distantes das áreas densamente urbanizadas, sendo cercadas de fragmentos de vegetação e intercalados com áreas de pastagem e corpos hídricos, como é o caso da Vila dos Sonhos em que se encontra próxima a represa Dr. João Penido, um dos principais mananciais de abastecimento do município.

Entretanto, observou-se que o resultado gerado pelo interpolador IDW apresenta limitações com relação a distribuição da temperatura, uma vez que o ponto 2, alocado na área de pasto, possui elevados valores de temperatura, mas que na representação espacial é representada dentro de polígonos com temperaturas menores. Esse fato demonstra que o produto ainda apresenta condições destoantes das encontradas na realidade. Portanto, é necessário avaliar esse tipo de mapeamento com o cuidado de relacionar com outros aspectos espaciais para gerar resultados mais consistentes. 
Partindo para além do zoneamento térmico traçado pelo interpolador, buscou-se relacionar as características térmicas do município, associados a fatores de relevo e de uso e cobertura do solo, sendo possível esboçar possíveis zonas topoclimáticas, como apresentado na figura 14.

No mapa a seguir foi possível visualizar a diferenciação de 34 classes topoclimáticas, as quais são resultados de combinações existentes em cada janela de análise com relação a temperatura, uso do solo e morfologia do terreno (a descrição de cada combinação pode ser visualizada na tabela 3). Dessa forma, verifica-se 4 grandes zonas de destaque representadas pelas cores verde, vermelho, roxo e amarelo. Com relação a área no entorno dos pontos 2 e 3 visualiza-se certa homogeneidade e a classe predominante dessa zona é a 352, com temperatura entre $17^{\circ} \mathrm{C}$ e $17,5^{\circ} \mathrm{C}$, com uso predominante de pastagem e morfologia de Degraus Reafeiçoados. Essa zona também é visualizada entre duas outras zonas formadas no entorno dos pontos 4 e 5 , marcando possivelmente uma área de transição.

As classes de maiores representatividades são as 452 (Temp. $17,5^{\circ} \mathrm{C}$ e $18^{\circ} \mathrm{C}$, Pastagem, Degraus Reafeiçoados) e 453 (Temp. $17,5^{\circ} \mathrm{C}-18^{\circ} \mathrm{C}$, Pastagem, Morros), com $31 \mathrm{mil}$ e $36 \mathrm{mil}$ hectares de extensão, sendo o relevo o componente que as diferencia. Uma área interessante encontra-se no entorno do ponto 1 , na classe 42 , com temperaturas entre $17,5^{\circ} \mathrm{C}$ e $-18^{\circ} \mathrm{C}$, uso de área antropizada e morfologia de degraus reafeiçoados, com 3300 hectares de extensão. Nessa localidade encontra-se uma potencial zona de expansão, a popularmente conhecida cidade alta.

A zona identificada na cor vermelha se apresenta apenas no entorno do rio Paraibuna, somando em todas as suas variações cerca de 24 mil hectares. Nessa área há variações principalmente atreladas a condições de relevo, uma vez que boa parte dessa área se encontra em uso de pastagem e na mesma faixa térmica.

Por meio desse esboço de traçado de unidade verifica-se a complexidade do objeto de estudo ao delimitar zonas homogêneas, visto a quantidade de ruídos encontrados entre as mesmas com quadriculas pulverizadas pelo município que, mesmo apresentando-se com representatividade de área, não se apresentam de forma espacialmente agrupadas. Dessa forma, na tabela 3, é possível visualizar o quantitativo de área de cada combinação traçada. 


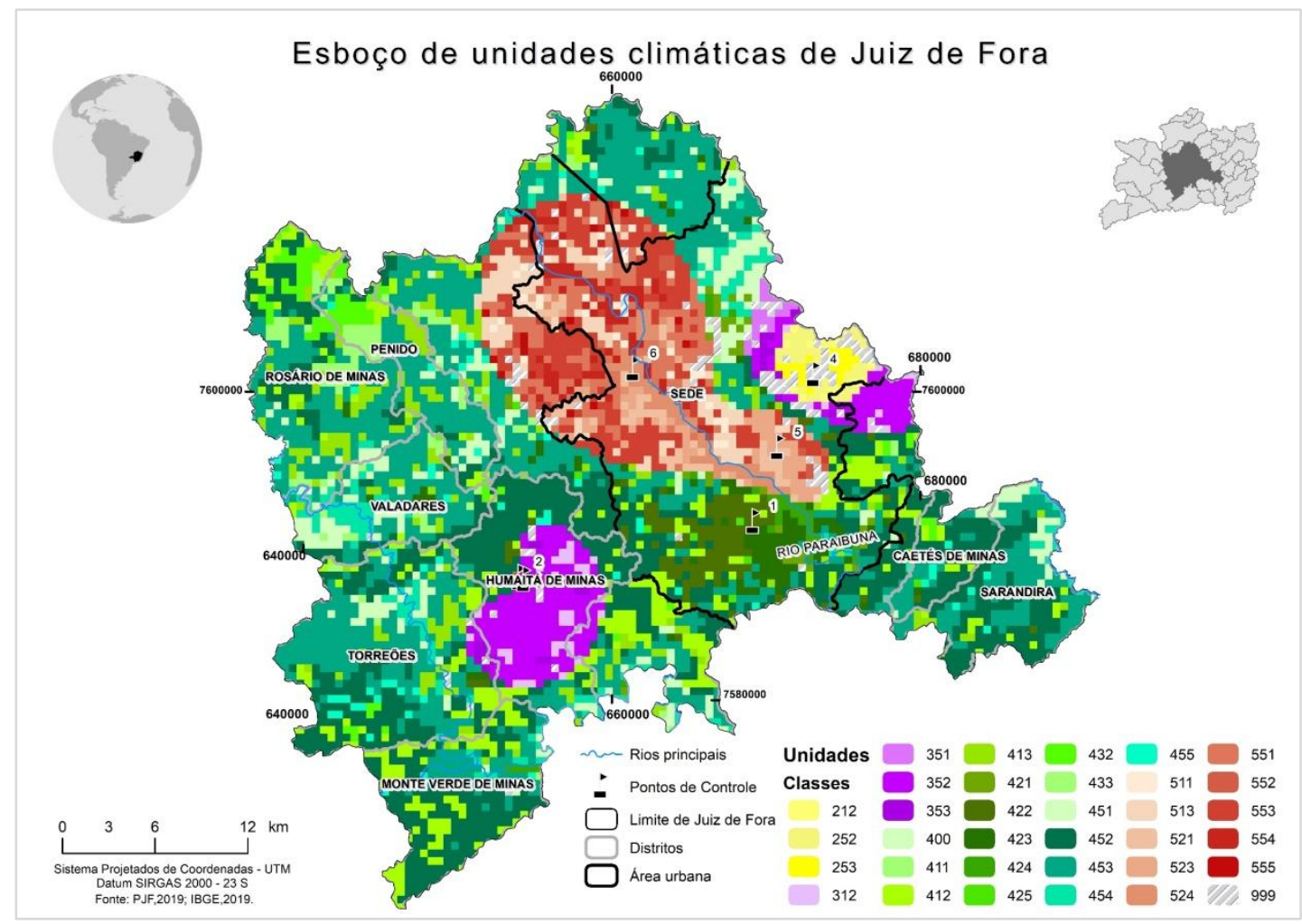

Figura 14 - Mapa com esboço das unidades topoclimáticas. Organizado pelos autores.

Tabela 3 - Descrição das classes do mapa de unidades topoclimática.

\begin{tabular}{|c|c|c|}
\hline 212 & Temp. 16.5-17ํC, Vegetação, Degraus Reafeiçoados & 375.0 \\
\hline 252 & Temp. 16.5-17ํㅡ, Pastagem, Degraus Reafeiçoados & 1175.0 \\
\hline 253 & Temp. 16.5-17으, Pastagem, Morros & 550.0 \\
\hline 312 & Temp. 17-17.5C, Vegetação, Degraus Reafeiçoados & 1250.0 \\
\hline 351 & Temp. 17-17.5드, Pastagem, Colinas & 625.0 \\
\hline 352 & Temp. 17-17.5ㄷ, Pastagem, Degraus Reafeiçoados & 6725.0 \\
\hline 353 & Temp. 17-17.5드, Pastagem, Morros & 775.0 \\
\hline 400 & Temp.17.5-18ㄷ, indefinido & 300.0 \\
\hline 411 & Temp.17.5-18으, Vegetação, Colinas & 600.0 \\
\hline 412 & Temp.17.5-18ㄷ, Vegetação, Degraus Reafeiçoados & 10525.0 \\
\hline 413 & Temp.17.5-18C, Vegetação, Morros & 6450.0 \\
\hline 421 & Temp.17.5-18으, Área Antropizada, Colinas & 900.0 \\
\hline 422 & Temp.17.5-18드, Área Antropizada, Degraus Reafeiçoados & 3300.0 \\
\hline 423 & Temp.17.5-18º, Área Antropizada, Morros & 2800.0 \\
\hline 424 & Temp.17.5-18ํㅡ, Área Antropizada, Planície Fluvial & 1025.0 \\
\hline 425 & Temp.17.5-18C, Área Antropizada, Planície Terraços & 300.0 \\
\hline 432 & Temp.17.5-18C, Silvicultura e Agricultura, Degraus Reafeiçoados & 2300.0 \\
\hline 433 & Temp.17.5-18ํㅡ, Silvicultura e Agricultura, Morros & 2550.0 \\
\hline 451 & Temp.17.5-18두, Pastagem, Colinas & 7625.0 \\
\hline
\end{tabular}


454 Temp.17.5-18ํㅡ, Pastagem, Planície Fluvial

511 Temp.>18ํㅡ, Vegetação, Colinas

513 Temp.>18ํㅡ, Vegetação, Morros

521 Temp.>18으, Área Antropizada, Colinas

523 Temp.>18ํㅡ, Área Antropizada, Morros

524 Temp.>18ํㅡ, Área Antropizada, Planície Fluvial

552 Temp.>18으, Pastagem, Degraus Reafeiçoados

553 Temp.>18ํㅡ, Pastagem, Morros

\section{CONSIDERAÇÕES FINAIS}

A partir desta pesquisa foi possível concluir que o uso do solo ligado a áreas de pastagem possui relevância na constituição das zonas térmicas do município. Além disso, através do esboço das unidades, foi possível observar minimamente a ocorrência de 7 zonas topoclimáticas distintas e aglutinadas, reproduzindo, até certo ponto, o mosaico multifacetado de organização da paisagem.

O objetivo de se chegar a um esboço de unidades foi atingido, fornecendo material para que em seguida seja possível refinar e consolidar a delimitação das mesmas. $E$, nesse sentido, o papel desempenhado pelas ferramentas de geoprocessamento e banco de dados permitiram ir além das zonas térmicas traçadas pelos interpoladores convencionalmente utilizados, contribuindo para adição de elementos importantes à análise.

É importante destacar que este trabalho faz parte de projeto de pesquisa em desenvolvimento e, portanto, ainda em construção. Para isso, pretende-se ampliar a rede de pontos de monitoramento, além de parcerias com outros pesquisadores, visando se aproximar ainda mais da realidade climática do município, tornando possível a identificação pormenorizada das unidades climáticas existentes e a utilização do documento produzido como ferramenta de planejamento territorial-urbano.

\section{REFERÊNCIAS BIBLIOGRÁFICAS}

ANUÁRIO ESTATÍSTICO. CPC - Centro de Pesquisas Sociais, Universidade Federal de Juiz de Fora. CD-ROM: Anuário Estatístico 2005. Juiz de Fora - 2005.

BARBOSA, H. P.; AMORIM, M. C. C. T. Clima urbano em Presidente Prudente/SP: diferenças térmicas e higrométricas urbano/rural em episódios de outono. Revista GeoNorte. 2012. 
BRITTO, Monique Cristine de et al. A dinâmica da violência: análise geográfica dos homicídios ocorridos em Juiz de Fora entre os anos de 1980 a 2012. 2013.Dissertação de Mestrado.

DENATRAN, Ministério das Cidades, Departamento Nacional de Trânsito, 2019.

ESRI, D. ArcGIS. version 10.5. 1. ESRI: Redlands, CA, USA, 2019.

IBGE. Censo Demográfico 2010.2 Disponível em: <http://www.censo2010.ibge.gov.br>. Acesso: Outubro/2019.

JARDIM, C. H. Construção e avaliação de desempenho de modelo de mini-abrigo meteorológico de ventilação passiva para experimentos em campo de climatologia. In. GALVANI, E.; GOBO, J. P. A.; LIMA, N. G. B. (Orgs.) Climatologia Aplicada Volume 2. Curitiba: CRV, 2018.

JARDIM, C. H.; GALVANI, E. Uso da Terra e Variações da Temperatura do Ar no Interior e Áreas Limítrofes ao Parque Nacional da Serra do Cipó, Minas Gerais. Revista do Departamento de Geografia, São Paulo, p. p.162-173, 2018.

JARDIM, C. H.; MOURA, F. P. Variações dos totais de chuvas e temperatura do ar na bacia do rio Pandeiros, norte do estado de Minas Gerais-Brasil: articulação com fatores de diferentes níveis escalares em área de transição climática de cerrado para semiárido. Revista Brasileira de Climatologia, v.1, p.168-189, 2018.

NETO, J. L. S. A. Decálogo da climatologia do sudeste brasileiro. Revista Brasileira de Climatologia, 1, 2005.

NIMER, E. (1979). Climatologia no Brasil. Série recursos naturais e meio ambiente, 4.

OLIVEIRA, D. E. ; ASSIS, D. C. ; FERREIRA, C. C. M. . Definição de unidades climáticas para a bacia hidrográfica do Rio Paraibuna, MG/RJ. In: XI Simpósio Brasileiro de Climatologia Geográfica, 2014, Curitiba-PR. Variabilidade e Mudanças climáticas globais: estudo da arte e perspectivas para a interação sociedade natureza. Curitiba: UFPR, 2014. v. 1. p. 734-747

PIMENTEL, F. O.; FERREIRA, C. C. M. Clima urbano: o uso de modelos geoespaciais na investigação do comportamento térmico em Juiz de Fora-MG. Revista Brasileira de Climatologia, v. 24, p. 49-66, 2019.

PJF, Plano Diretor Participativo do Município de Juiz de Fora MG, 2018.

RIBEIRO, A. G.. As escalas do clima. Boletim de Geografia Teorética, v. 23, n. 45-46, 1993.

ROMERO, M. A. B. Princípios Bioclimáticos para o Desenho Urbano - Projetos Editores Associados Ltda. São Paulo, Brazil, 1998.

SAUER, C. O., The morphology of landscape. Publications in Geography n. 2, p. 19- 53. Berkeley, University of Califómia, 1925.

SILVA, T. M. (2002). A estruturação geomorfológica do Planalto Atlântico no Estado do Rio de Janeiro. Rio de Janeiro, 265.

TORRES, F.T. P. Relações entre fatores climáticos e ocorrências de incêndios florestais na cidade de Juiz de Fora (MG). Revista Caminhos de Geografia, 2006 